Journal of Accident and Emergency Medicine 1995 12, 240-250

\title{
Abstracts of the BAEM Conference, April 1995, Torquay, UK
}

\section{BAETA PAPERS}

\section{Topical anaesthesia for children's lacerations - an acceptable approach}

J.M. KENDALL, ${ }^{1}$ A. CHARTERS ${ }^{2}$ \&

S.E. MCCABE

${ }^{1}$ Accident and Emergency Department, Frenchay Hospital, Bristol ${ }^{2}$ Department of Paediatrics, Derbyshire Royal Infirmary and ${ }^{3}$ Gloucestershire Royal Hospital Accident and Emergency Department

This paper presents the use of a topical gel preparation of adrenaline and cocaine (AC), as a local anaesthetic in the management of children's lacerations, and compares its anaesthetic efficacy with conventional intradermal lignocaine.

\section{Methods}

Children (aged 3-16 years) with lacerations (not of the digits or mucous membranes) were consecutively assigned to receive either $A C$ or lignocaine.

Pain scores, as perceived by patients, parents and staff, were measured conventionally (using Wong Baker faces and visual analogue scales) on administration of the local anaesthetic, and on suturing the wound, in the AC group $(n=56)$ and in the lignocaine group $(n=51)$.

\section{Results}

Mean pain scores on administration of the anaesthetic in the $A C$ group (mean $A C$ ) were significantly lower than in the lignocaine group (mean L), as perceived by the patient (mean $A C=1.70$, mean $\mathrm{L}=6.10, P<0.001$ ), the parent (mean $\mathrm{AC}=0.64$, mean $\mathrm{L}=5.40, P<0.001$ ), and the staff (mean $A C=0.65$, mean $L=5.40, P<0.001$ ). There was no significant difference in pain scores between the two groups on suturing the wounds, as perceived by patient (mean $A C=4.50$, mean $L=4.40$ ), parent (mean $A C=3.10$, mean $L=3.80$ ), and staff (mean $A C=2.62$, mean $L=3.60$ ). On direct questioning the overall procedure was considered acceptable by $84.5 \%$ of parents in the $\mathrm{AC}$ group compared with $61 \%$ of parents in the lignocaine group $(P<0.01)$.

\section{Conclusion}

Topical AC should be considered the local anaesthetic of first choice for suturing appropriate children's lacerations.

\section{Aortic injuries in South-East Scotland}

R. LONGMAN, J.P. WYATT, D. BEARD, D. STEEDMAN, C.E. ROBERTSON

Accident and Emergency Department, Royal Infirmary, Edinburgh

Data on all patients sustaining aortic injuries amongst the 0.83 million people living in Lothian and Borders was collected prospectively over 2 years by the Scottish Trauma Audit Group and Edinburgh University Forensic Medicine Department. Post-mortems were performed for all deaths and ISS calculated.

Fifty-five patients (41 males) sustained aortic injuries: $34(62 \%)$ were aged less than 40 years. The commonest mechanisms of injury were road traffic accidents (38 injuries) and falls (10 injuries). Fifty-two injuries followed blunt injury and, three followed penetrating injury. Only 13/55 patients reached hospital alive: only two of these survived. Although arriving moribund at hospital, the diagnosis for several patients was delayed. Many patients had unsurvivable injuries: 35 had unsurvivable aortic injuries (AIS $=6$, ISS $=75$ ), 10 had unsurvivable head injuries and five had unsurvivable abdominal injuries. Most injuries involved the thoracic aorta at the level of the ligamentum arteriosum.

The low rate of aortic injuries presenting to hospital (6.6 patients per million population per year), combined with the proportion with significant extrathoracic injuries and high mortality, have im- 
Abstracts of the BAEM Conference April 1995 plications for the planning of trauma services. Aortic injury should be suspected from the mechanism of trauma and associated injuries. The type and site of aortic injures following blunt trauma in this study support the theory that the mechanism of injury is an 'Osseous Pinch', which has superceded the old theory of differential deceleration of aortic segments.

\section{Taking a chopper to TRISS: who benefits?}

P.A. YOUNGE, T.C. COATS, M. DAWSON, D. GURNEY, C.J.C. KIRK, A.W. WILSON

The Royal London Hospital

Patients treated by the Helicopter Emergency Medical Service (HEMS) trauma system are compared with patients in the Major Trauma Outcome Study (MTOS).

\section{Methods}

Data were collected prospectively on HEMS trauma system patients over a 4-year period. After excluding penetrating trauma (94) and missing data (46) a group of 692 patients were assigned a probability of survival using TRISS. Standard outcome measures ( $W, Z$ and $M$ statistics) were used initially. $M$ did not allow comparison due to injury severity mix differences. Comparison was made across six subsets selected by probability of survival and a new base line allowing for TRISS predictive power was established.

\section{Results}

Significant improvements in survival of HEMS patients as compared to MTOS were found in three subsets, the subset with a 26 to $50 \%$ probability of survival having 20 excess survivors per 100 cases $(P=0.001)$. Subset comparisons between HEMS and MTOS and within the HEMS group showed those with an improved chance of survival to have more serious head injuries $(P=0.03)$ and a multi system pattern of injury $(P=0.005)$.

\section{Conclusions}

(1) A modified TRISS comparison using probability of survival selected subsets with a row base line can be used to reveal differences in out-
(2) Certain severely injured patients, who have more head and multi-system injuries can benefit from the HEMS trauma system.

\section{Detection of a small haemorrhage using stroke distance}

J.M. HANSON ${ }^{1}$, E. KIRKMAN, M.A. HORAN ${ }^{2}$ \& R.A. LITTLE

North Western Injury Research Centre and Departments of ${ }^{1}$ Emergency and ${ }^{2}$ Geriatric Medicine, University of Manchester

Failure to recognize blood loss contributes to a number of preventable deaths following injury and reflects shortcomings in the assessment of haemorrhage: blood pressure (BP) is maintained by the baroreflex until blood loss is severe, while heart rate (HR) changes can be biphasic. A better indicator of early blood loss are changes in stroke volume which should fall early in haemorrhage (Starling's Law of the Heart), and may be assessed non-invasively as stroke distance (SD) using continuous wave Doppler ultrasound. Control studies using lower body negative pressure to simulate haemorrhage suggested that SD may be more effective at assessing early blood loss than HR or BP.

Nine volunteers (aged 21 to 48) donated $450 \mathrm{~mL}$ of blood for the Blood Transfusion Service. HR, BP and SD (PUFFIN, DELTEX INTERNATIONAL) were monitored before and immediately after donation. BP increased slightly from $90 \pm 3$ to $96 \pm 4 \mathrm{mmHg}$ while HR and pulse pressure did not change significantly from the pre-donation levels. By contrast SD fell significantly by $3.3 \pm 0.5$ from $22.2 \pm 0.9 \mathrm{~cm}$ $(P<0.05$, paired $t$-test). These results indicate that stroke distance provides a more sensitive indicator of small volume blood loss than heart rate or blood pressure, and may be useful for the early detection of haemorrhage.

\section{An undergraduate core curriculum for accident and emergency medicine}

\section{R.D. HARDERN}

\section{Accident and Emergency Department, The} General Infirmary, Leeds

An undergraduate core curriculum for accident and emergency (A\&E) medicine was developed using Spivey's technique. The views of general practitioners (GPs) and consultants in other specialties, as well as of A\&E staff (consultants, trainees and 
Abstracts of the BAEM Conference April 1995 senior house officers) were sought (20 replies received).

The following were felt to be essential elements of this core.

\section{(1) Resuscitation}

Basic life support teaching and certification (including paediatric basic life support). Recognition and management of arresting rhythms. Use of a defibrillator. Bag-valve-mask ventilation.

\section{(2) Trauma}

ATLS: principles, primary survey, shock, secondary survey, limb trauma, thermal injuries, Cervical spine immobilization, log rolling and limb immobilization. Soft tissue injuries (including the hand and wrist). A\&E management of common fractures and dislocations.

\section{(3) Wounds}

Wound care. Tetanus prophylaxis. Dressings and bandages. Suturing.

\section{(4) 'Medical' topics}

Poisoning: initial management, recognition of toxidromes, management of specific poisons. Chest pain. Cardiac emergencies. Respiratory emergencies. Collapse, syncope and unconsciousness. Dyspnoea. Neurological emergencies.

\section{(5) Non-trauma 'surgical' topics}

Abdominal pain. Soft tissue infections.

\section{(6) Practical procedures}

Peripheral venous cannulation. Central venous cannulation. ECG recording and analysis. Arterial blood gas sampling and analysis.

\section{(7) Miscellaneous topics}

Ethanol problems and A\&E. Paediatric emergencies. Radiology in A\&E. Pain control in A\&E. Environmental emergencies.
Suicidal risk assessment of deliberate overdose patients in the accident and emergency department using a pro-forma

\section{SEAN J. McGOVERN \&}

\section{B. THORTHON}

Belfast City Hospital, Belfast, Northern Ireland

There has been a recent trend to discharge some parasuicide patients from the accident and emergency (A\&E) department with potential financial savings although this remains controversial ${ }^{1,2}$. Proformas have been used to improve psychiatric evaluation in the in-patient setting.

The objective of the study was to assess whether A\&E doctors with no formal psychiatric training could make a valid suicidal risk assessment in an acute situation using a pro-forma. A prospective 3-month pilot study comparing A\&E senior house officers' pro-forma evaluation with that of an experienced psychiatrist was undertaken in an urban teaching A\&E department. Subjects comprised deliberate overdose patients excluding those who required admission on medical grounds.

\section{Results}

A total of 61 patients were entered into the study. Of these $51(87 \%)$ underwent psychiatric evaluation, 42 were considered low suicidal risk by the psychiatrist. The A\&E doctor evaluation concurred in $\mathbf{3 9}$ (93\%), over-evaluating suicidal risk in three cases. Nine patients were considered high suicidal risk by the psychiatrist, A\&E doctors predicted six $(66 \%)$ of these. Past psychiatric history was undervalued by A\&E doctors when making their assessments.

\section{Conclusion}

The use of pro-formas alone by A\&E SHOs to assess suicidal risk would not support the case for deliberate overdose patients direct discharge from the A\&E department.

\section{References}

1. Owens D. (1990) Self-harm patients not admitted to hospital. Journal of the Royal College of Physicians of London, 24(4), 281-283.

2. Waterhouse J. \& Platt S. General hospital admission in the management of parasuicide. (1990) A randomised control trial. British Journal of Psychiatry 156, 236-242. 
Abstracts of the BAEM Conference April 1995

\section{ASPECTS OF TRAUMA}

\section{Traumas in Transylvania}

\section{S. MAURICE}

Accident and Emergency Department, Royal Infirmary of Edinburgh, Edinburgh

In June 1994 a disused theatre suite was dismantled in Dunfermline, driven across Europe in pieces on a convoy of trucks and rebuilt in the Transylvanian town of Tirgu Mures. On 30 July the first accident and emergency department in Romania opened its doors to the public. Prior to this, structured emergency medical care did not exist in Romania. The paper describes the building and establishment of the department and the case-mix of the first 300 patients presenting to the new department. The paper also discusses the problems faced introducing a new system of medical care into an East European country still living in the shadow of communism.

\section{Pre-morbid medical conditions in trauma patients}

\section{T. WARDLE,' P. DRISCOLL, C. OXEBY, ${ }^{1}$ M. WOODFORD ${ }^{1} \&$ F. MUNSAL ${ }^{2}$}

University Departments of 'Emergency Medicine and ${ }^{2}$ Orthopaedics, Hope Hospital, Salford

It is well recognized that age has a direct effect on the outcome of trauma patients. ${ }^{1}$ Work from selected centres in the United States indicates that pre-morbid medical conditions (PMC) also have an effect. ${ }^{2,3}$ However, the incidence of PMC in these studies varied between 4.8 and $19.0 \%$ and was therefore considered not to be an important factor in overall mortality. ${ }^{2,3}$

In contrast, we have shown in a recent retrospective study that PMC were present in $39 \%$ of UK trauma patients with complete records (Wardle, personal communication). In view of the incidence of incomplete documentation, it could be argued that this figure was artifically high. Therefore the aim of this study was to carry out a detailed investigation in one UK centre to ascertain the incidence of PMC and determine how this varied with age.

All the 1100 trauma patients eligible for inclusion into MTOS(UK), and who had entered Hope Hospi- tal between 1988-90, were studied. Their data were analysed for PMC, age and outcome. The medical conditions were grouped as follows: cardiovascular, respiratory, metabolic, neurological, and others.

Overall $37 \%$ had PMC and $6 \%$ died. The most common PMC was cardiovascular, in particular ischaemic heart disease. This occurred in $11 \%$ of cases. Its incidence increased with age but it was still present in $1 \%$ of patients of less than 45 years. The most common PMC in this younger age group was respiratory - occurring in $3 \%$ of cases. Metabolic conditions declined with age $(2 \%$ in the under 45 years group and $1 \%$ in those over 65 ). Neurological conditions were reasonably constant at approximately $1 \%$ in all age groups.

Consequently traumatologists must be aware that co-existing medical problems are common in UK trauma victims. As these can have a profound effect on the evaluation and management of these patients, it is essential that an accurate medical history is obtained and appropriate investigations carried out.

\section{References}

1. Bull J. \& Dickson G. (1991) Injury scoring by TRISS and ISS/age. Injury 22, 127.

2. Milzman D.,BoulangerB., RodiguezA., Soderstrom C. Mitchell K. \& Magnant C. (1992) Pre-existing disease in trauma patients: A predictor of fate independent of age and injury severity score. Journal of Trauma 32, 236.

3. Sacco W., Copes W., Bain L. et al. (1993) Effect of pre-injury illness on trauma patient survival outcome. Journal of Trauma 35, 538.

\section{The cost of litigation in accident and emergency departments}

\section{HULBERT ${ }^{1} \&$ W. RIDDLE ${ }^{2}$}

'Accident and Emergency Department, Ealing Hospital NHS Trust and ${ }^{2}$ North West Thames Accident and Emergency Audit Group

It has traditionally been thought that the cost of litigation in accident and emergency (A\&E) departments has been high.

The North West Thames Accident and Emergency Audit Group was established in 1989 to undertake audit at both a departmental and a regional level. The group consists of representatives of the A\&E departments of Ashford, Ealing, Hillingdon and West Middlesex hospitals.

These departments see a total of approximately 215000 patients per year and cover a large per- 
centage of the catchment area of North West Thames.

Litigation against all the A\&E departments over a 2-year period was reviewed and the following criteria examined: (1) nature of complaint, (2) length of time case open, (3) costs involved, and (4) amount involved.

The results showed that what had traditionally been thought of as a high litigation area was, in reality, one of small settlements and short time spans. The average number of new cases per year is four with the average settlement time being 18 months. On average only $60 \%$ of cases brought against the A\&E department go to court with the remainder being either settled before court or are not pursued after initial solicitor's consultations.

Settlement figures are small, with the average amount being $£ 5000$, usually for injuries causing long term disability. These result normally from orthopaedic injuries which have been either mismanaged or misdiagnosed.

Those that have gone to court settle for amounts on average of $£ 9000$ and those that have settled out of court have been settled for amounts on average of $£ 1200$. The average costs were found to be in the region of $£ 600$. This was an average of the total of both the departments and the plaintiff's costs.

A\&E medicine has traditionally been seen as a high litigation area with quick and frequent decisions being made on patient care. High patient workloads and a history of staff shortages have produced the assumption that the A\&E department is a high litigation area.

The major component of litigation would appear to be the failure to diagnose and treat a range of bony injuries. The settlements involved are surprisingly small, compared with those of other specialities such as obstetrics, where it is not uncommon to find settlements of half a million pounds upwards. This study has shown that this is not the case.

\section{Geriatric blunt trauma in Scotland}

\section{P.T. GRANT \& G.W. MCNAUGHTON}

Accident and Emergency Department, Western Infirmary, Glasgow, G11 6NT

The purpose of this study was to ascertain the current level of management of elderly blunt trauma victims in Scotland, particularly comparing them with younger patients, in an effort to identify any factors which may contribute to the poorer outcomes from trauma in elderly people.

\section{Methods}

This prospective study was conducted under the auspices of the Scottish Trauma Audit Group (STAG) with patients being followed daily by independent audit staff.

\section{Results}

During the period February 1992-January 1994, 4439 patients were analysed, 1239 of whom were over 65 years of age. There was no significant difference between the two groups regarding the seniority of medical staff involved in any key aspect of their care. Similarly, comparable rates were found for internal fixation of long bone fractures, and transfers to a regional neurosurgical service. However, the intensive care admission rate was significantly lower for elderly people $(P<0.01)$. For those with ISS $>15,53.3 \%$ of younger patients were admitted to intensive care units compared with only $43.3 \%$ of elderly patients, $(P<0.05)$.

\section{Conclusions}

We should dispel the myth that elderly people always 'do badly' when traumatized, and adopt a more aggressive attitude to their management particularly with respect to intensive care admission.

\section{Medical control of pre-hospital care - lessons from Houston (Maurice Ellis Scholarship 1994)}

\section{G. JOHNSON FRCS}

Accident and Emergency Department, Derriford Hospital, Plymouth \& Torbay Hospital, Torquay

The Ambulance Services of this country are currently embarked upon a training programme which will result in the presence of a paramedic on 
Abstracts of the

BAEM Conference

April 1995 every emergency ambulance by 1995 . The provision of pre-hospital advanced life support by paramedics in the United States has preceded that in the UK and has evolved through a phase where a perceived absence of medical involvement in the control of pre-hospital care resulted in inappropriate field interventions and prolonged pre-hospital times.

The City of Houston Emergency Medical Service (EMS) under the directorship of Dr Paul Pepe has developed a model of intense and enthusiastic physician involvement in all aspects of pre-hospital care from paramedic training through continuous quality assurance to research into the appropriateness of specific interventions. By this method quantitative improvements in the quality of the service have been demonstrated.

The presentation is the result of the author's visit to the EMS as the Maurice Ellis scholar.

\section{The Levant Man Engine disaster}

\section{J. MARROW}

Arrowe Park Hospital, Upton, Wirral, Merseyside, L49 5PE

The dangers of coal mining, with special risk of fire and explosion, are well recognized. Metalliferous ores are usually mined without the problem of flammable and explosive gases but underground workings, sometimes at great depth, have obvious intrinsic dangers. Valuable minerals have often been extracted at great human cost. Sometimes devices introduced to improve the conditions miners work under have brought their own hazards.

By reference to contemporary newspapers and documents, I will describe the man engine, a remarkable device used to lower and raise miners before modern winding gear was introduced. I shall discuss the humanitarian reasons for the adoption of this device, including recommendations following a completely different fatal accident in the Snaefell Mine on the Isle of Man in 1897. I shall describe some of the safety measures required of those operating man engines.

In the Levant Mine in western Cornwall, in October 1919, a metal strap at the top of the man engine broke, causing fatal injury to 31 men. About 19 more were injured but survived. I shall briefly describe the rescue operations which followed the disaster and some of the local and national reac-
FREE PAPERS

\section{Primary care in accident and emergency departments - ups and downs}

\section{J. SLOAN \& D. ROBINSON}

\section{Accident and Emergency Department, Leeds General Infirmary, Leeds}

In this paper the recent move towards provision of primary care within accident and emergency (A\&E) departments is discussed, with reference to various options that have been applied in Leeds.

\section{Establishing and evaluating an A\&E primary care clinic}

During September 1993, with the benefit of locally organized research funding, a full-time evaluation of all the department's attendances was carried out. Over 7000 cases were analysed, and many indicators of the 'primary care patient' were found. These are presented.

As a result of this work, in January 1994 we set up a regular primary care clinic in the department, funded from our own budget. The hours and working patterns are presented.

\section{How it was developed}

General practitioners (GPs) were not keen on the concept of a primary care clinic. Their overall view was that primary care patients should be sent back to their GP immediately on presenting to the A\&E department. The view taken by the A\&E purchaser, Leeds Healthcare, was similar. We describe new triage criteria that were developed to enable us safely to identify clear primary care cases and then re-direct them to their GPs.

Almost immediately we began to discover the enormous opportunities for the triageur. Patients ideally need personally tailored care, and we started to consider directing patients from triage to other sources of care (Fig. 1). Some of these had been obvious, but many new possibilities emerged.

We believe that it is possible for A\&E departments to respond constructively to all presenting patient's needs, without losing the focus of the department's main purpose - to provide timely critical care, or diverting significant resources away from that focus. 
Abstracts of the

BAEM Conference

April 1995 ternatives for developing primary care in A\&E medicine, how primary care should be managed within A\&E departments in the future in relation to the current training schemes and workforce situation in A\&E departments.

\section{Measurement of patient satisfaction after implementation of a formal triage system in accident and emergency departments}

\section{F. WATTS, E. PAYNE, L. MORRISON \& S. MCCABE}

\section{Accident and Emergency Department and Health Psychology Unit \& Gloucestershire Royal Hospital}

Previous research failed to demonstrate increased patient satisfaction following triage introduction. ${ }^{1}$ The objective of this study was to assess patient and staff satisfaction before and after introduction

Fig. 1 Referral pathways

\section{Primary care in accident and emergency medicine?}

\section{I.R.S. ROBERTSON-STEELE}

Accident and Emergency Department, The Royal Hospital, Wolverhampton

Primary care and the development of primary care consultants in accident and emergency (A\&E) medicine is a contentious issue at the present time. The definition of primary care in A\&E medicine is not yet adequately formulated. My paper offers a resource based definition of a primary care attender, discusses initial assessment and is based on a study of 5600 attenders in an urban A\&E environment over a 28-day period.

I propose then to discuss the issue of who should be treating these primary care attenders who constitute a significant workload in the population in Wolverhampton. I will discuss the issue of what role, if any, the A\&E department should have in relation to general practice 'out-of-hours' cover.

I will offer a proposed training scheme for consultants in primary care and compare and contrast this with the A\&E training scheme. I will discuss the current General Practice Vocational Training Scheme and the MRCGP examination.

\section{Methods}

A self-administered questionnaire consisting of closed and open-ended questions was given to1000 new attenders (ambulant patients only). This was followed by a staff questionnaire, which was completed pre-and post-triage training ( $37 \mathrm{~h})$.

Main outcome measures were based on patient satisfaction regarding: (1) waiting time expectations; (2) anticipated investigation and treatment;

(3) nature and severity of injury established;

(4) quality of information given; (5) organization of A\&E service; and (6) staff satisfaction.

\section{Results}

(1) Patient triaged 'much more rapidly' than expected $(P<0.001)$.

(2) $81 \%$ triaged $<5$ min.

(3) Overall, people felt significantly more welcomed into the department $(P<0.001)$.

(4) Overall impression of departmental organization improved dramatically $(P<0.002)$.

(5) Satisfaction with level of information given was significantly higher in all cases $(P<0.001)$.

(6) No change in overall opinion of quality of care, however, pre-triage results had been highly encouraging, trending towards better end of the scale. 


\section{Conclusions}

(1) Triage by a nurse is what the patients (and the Government) want and results in significantly increased satisfaction levels $(P<0.001)$.

(2) The Patient's Charter 5-min standard is unrealistic (to patient)?

(3) Patients feel informed and more welcomed into an 'organized' A\&E department.

\section{Reference}

1. George S., Read S., Westlake L., Williams B., FraserMoodie A. \& Pretty P. (1992) Evaluation of nurse triage in a British A\&E department. British Medical Journal 304, 876-887.

\section{Can nurse practitioners interpret radiographs? A multicentre study}

S.J. MEEK,' J. KENDALL, P.A. YOUNG, J. PORTER, A,. SAUVAGE, ${ }^{3}$ C. MANN ${ }^{2} \&$ B. BROOKS $^{4}$

'Frenchay Hospital, Bristol, ${ }^{3}$ Queen Alexandra Hospital, Portsmouth, ${ }^{3}$ County Hospital, Lincoln \& 4St Bartholomews'2 Hospital, London

\section{Summary}

Nurse practitioners skill at interpreting radiographs is significantly inferior to that of experienced accident and emergency (A\&E) senior house officers (SHOs). There was a trend in our study towards better scores from nurse pratitioners than novice SHOs, but this was not statistically significant. Specific training in radiograph interpretation, and length of experience as a nurse practitioner did not correlate with ability to interpret radiographs.

\section{Aims}

To assess nurse pratitioners ability to interpret radiographs by comparison with A\&E SHOs.

\section{Method}

Twenty radiographs of distal limbs following trauma were shown to 45 nurse practitioners, 27 experienced SHO's (more than 5 months experience in A\&E) and 28 novice SHOs (less than
2 months such experience) under exam conditions. Subjects were recruited in seven A\&E departments between January and March 1995.

Results

\begin{tabular}{lrl}
\hline & Mean Score \\
\hline Experienced. SHOs & $63 \%$ & $P=0.02$ \\
Nurse Practitioners & $55 \%$ & $P=0.07$ \\
Novice SHOs & $48.5 \%$ & \\
\hline
\end{tabular}

The experienced SHOs scored significantly higher than nurse practitioners; The difference between the nurse practitoners and the novice SHOs was not sigificant.

Analysis of the nurse practitioner group according to 'training in radiograph interpretation' revealed no significant difference in ability to interpret radiographs between those with such training and those without (trained: $54 \%$, untrained $57 \%$. $P=49$.).

Analysis of the nurse practitioner group according to length of experience as a nurse practitioner revealed no correlation between ability to interpret radiographs and experience.

\section{Conclusions}

Nurse practitioners' ability to interpret radiographs is inferior to experienced SHOs and probably superior to novice SHOs, but larger numbers are required. The training given to nurse pratitioners in the technique does not lead to improved ability and should be reviewed.

Simple, safe and sound: a prospective comparison of Bier's block and haematoma block in the management of Colles' fracture

J. KENDALL, P. ALLEN, P. YOUNGE, S. MEEK, S. MCCABE

Gloucestershire Royal and Frenchay Hospitals

Our postal survey of 150 accident and emergency (A\&E) departments has shown a marked increase in haematoma block usage for Colles' fracture reduction over the last 5 years. This technique is now used as commonly as Bier's block. 


\section{Methods}

The purpose of this study is to prospectively compare patients randomly allocated to three groups, one using Bier's block and two using alkalanized or non alkalanized lignocaine for haematoma block. Pain scores at presentation, administration, reduction and $30 \mathrm{~min}$ post-reduction as well as transit times through the departments were collected. Patients are currently being followed up at 3 months and assessed radiologically and functionally.

\section{Results}

Transit times and pain scores for the first 100 patients are presented demonstrating that haematoma block is less painful on administration than Biers block $(P=0.02)$. Both show comparable patient flow and analgesia on reduction. In addition there was a trend for better first time radiological reduction using haematoma block, with fewer immediate remanipulations in the accident department.

\section{Conclusions}

(1) Haematoma block is less painful to administer than Bier's block.

(2) Comparable analgesia during reduction is achieved.

(3) Patient flow is similar for both blocks.

(4) There may be better radiological reduction with haematoma block.

\section{Thunderstorm asthma in accident and emergency departments in London}

\section{D.N. WALLIS \& J.F.W. WEBB}

Accident and Emergency Departments Newham

General Hospital and St Thomas' Hospital, London

Between 24 and 25 June 1994 accident and emergency (A\&E) departments in London experienced an epidemic of patients with asthma, thought to have been related to the severe thunderstorm on the night of 24 June 1994. The aim of the study was to delineate the time course of the epidemic, to characterize the patients in the epidemic, and to assess the demand on resources. The study was carried out in eight A\&E departments in London.

\section{Methods}

$A \& E$ registers and records were examined.

\section{Results}

Patients in the epidemic were characteristically between 20 and 40 years old. Overall $47 \%$ of patients were not known to have ever had asthma, while $62 \%$ had a history of hay fever. A total of $76 \%$ were discharged from A\&E. The demand on resources (particularly medication and equipment) was considerable.

\section{Discussion}

The results together with data on pollen counts and features of the thunderstorm, suggest that bronchoconstriction may have been precipited in susceptibleindividuals by aeroallergernsuspended by the thunderstorm. The epidemic has implications as a form of major incident. Most patients were not seriously ill although obviously diversion of patients to other hospitals would difficult if all hospitals in an area were affected. There may be a possibility of alerting A\&E departments and the public to conditions predisposing to such an epidemic in the future.

\section{Electrical storms and an asthma epidemic: a flash in the pan?}

C.V. EGLESTON, ' G. CAMPBELLHEWSON, ${ }^{2}$ U. ALLLIT ${ }^{3}$ \& S.M. ROBINSON ${ }^{2}$

\section{Accident and Emergency Departments, 'Addenbrooke's Hospital Cambridge, ${ }^{2}$ Peterbrough District Hospital, and ${ }^{3}$ Aerobiologist, Cambridge}

On the night of 24 and early morning of 25 June 1994 electrical storms occurred over much of the 
Abstracts of the BAEM Conference April 1995
United Kingdom. Our two units experienced equivalent sized marked increases in asthma attendances at this time (21 attendances in each unit when the expected asthma attendance during a 24-h period at this time of year would normally be one or two patients in each unit). Fifteen patients $(35.7 \%)$ had no previous history of asthma. Throughout the country there was speculation that the increase in asthma attendances could be related to electrical storm activity. However electrical storm activity measured in our two catchment areas by ground to ground and ground to air lightning strikes differed markedly (two strikes in one area and 37 in the other). We could find no significant correlation between asthma attendances and electrical storm activity.

At this time atmospheric pollution was high (zerolevel ozone had a daily average of $45 \mathrm{ppb}$ ) as were levels of fungal spores such as Phaespheria nigrans (max concentration reached was 13987 spores/ cubic metre/hour). Given that these other causative factors were present we feel that the increase in attendances should not be attributed to electrical storm activity per se.

\section{Accident and emergency and occupa- tional therapy departments working together to limit falls in elderly people}

\section{S.J. MCGOVERN \& C.J. FOY}

\section{Belfast City Hospital, Belfast, Northern Ireland}

Since November 1993 the Belfast City Hospital occupational therapy (OT) department has offered immediate ( $<24 \mathrm{hrs)}$ assessment of elderly people (>70 years of age) who have presented to the accident and emergency (A\&E) department as a result of a fall and who were deemed eligible for discharge home. Patients were referred for OT assessment and intervention provided they met more than two criteria on a specially designed screening pro-forma.

This paper describes the setting up of such a system and presents a summary of the first year's work in an urban teaching hospital with 50000 new attendances per annum.

\section{Results}

Fifty-three patients were referred and 45 (85\%) re- ferred were those living alone, with a history of falls or decreased mobility. Sixteen $(30 \%)$ of these were referred to community OT for appliances and 10 $(19 \%)$ were referred to the social worker. Five (10\%) were referred to the physiotherapist. Nine $(17 \%)$ patients, despite relatively minor injury, were found to require admission and five refused treatment.

\section{Conclusion}

Liaison between the A\&E and OT departments provides a good screening system for those elderly people who have fallen and are at risk of falling again. The use of a screening pro-forma reduces the number of patients so referred to levels which will not disrupt the working of the OT department making this system attractive to other hospitals as form of accident prevention in elderly people.

\section{The role of ultrasound in the emergency department - a USA/UK comparison}

\section{M.J. CLANCY \& K.J. TAYLOR}

Department of Accident and Emergency Medicine, Bristol Royal Infirmary \& Department of Radiology, Yale University, New Haven, Connecticut

Ultrasound provides rapid, portable and noninvasive imaging of patients in the emergency department. There is a need in these patients to exclude correctable conditions rapidly, where the initial differential diagnosis is often wide and the risks of transfer for more detailed imaging are considerable.

Over a 20-week period all ultrasound reports of emergency department patients at Yale New Haven Hospital, Connecticut, and St James University Hospital, Leeds, were reviewed in order to identify any differences in the use of ultrasound between the two departments.

\section{RESULTS}

A total of 309 reports were reviewed (excluding obstetric and gynaecological cases). Ultrasound examinations were undertaken in 1 in 104 new patients attending the Emergency Department of Yale New Haven Hospital and 1 in 485 patients attendingStJames University Hospital. In otherwords, almost a fivefold difference in frequency of the examination. 
A detailed review will be presented of the different way ultrasound was used by the two departments in the assessment of acute abdominal complaints, cardiac problems, testicular problems, detection of venous thrombosis and other cases.

No attempt has been made to assess the usefulness of ultrasound in this paper but the fivefold variation in the frequency of use of this imaging modality strongly indicates that there is a need for a clear definition of the role of ultrasound within emergency medicine.

\section{An analysis of the effects of British Summer Time on road traffic accidents in Cheshire}

\section{J. WHITTAKER}

Registrar in Accident and Emergency, Mersey Regional Training Scheme

In the light of recent calls for the introduction of year round British Summer Time (BST), the object of this study was to establish whether the annual change from Greenwich Mean Time (GMT) to BST had a discernible effect on the frequency and types of road traffic accidents (RTAs) in Cheshire.

\section{Methods}

Data were obtained from a database of police accident reports. Two-week periods either side of the change in hours in the spring and autumn were analysed over a period of eleven years. Analysis concentrated on the daily peaks in RTAs over 4-h periods in the morning and evening.

\section{Results}

Information from a total of 4185 casualties was studied. The onset of BST in spring was associated with reductions in the total numbers of RTAs in both the morning and evening periods in spite of the darker mornings. The reversion back to GMT in autumn was however, associated with a significant increase in total casualties in the evening period.

\section{Conclusion}

The use of BST has a beneficial effect on casualty numbers from RTAs in Cheshire and the introduction of year-long BST may result in an overall reduction in RTA casualties. 